\title{
Impact of empagliflozin on right ventricular parameters and function among patients with type 2 diabetes
}

\author{
Bradley Sarak ${ }^{1,2}$, Subodh Verma ${ }^{2,3,4}$, C. David Mazer ${ }^{2,5}$, Hwee Teoh 4,6, Adrian Quan ${ }^{4}$, Richard E. Gilbert ${ }^{2,6}$, \\ Shaun G. Goodman 1,2,3, Karan Bami 1,2, Otávio R. Coelho-Filho7, Vineeta Ahooja ${ }^{8}$, Djeven P. Deva 2,3,9, \\ Vinay Garg ${ }^{1,2}$, Sumeet Gandhi ${ }^{2,10}$, Kim A. Connelly ${ }^{1,2,3^{*}}$ (D) and Andrew T. Yan ${ }^{1,2,3^{*}}$
}

\begin{abstract}
Background: Sodium-glucose cotransporter 2 (SGLT2) inhibition reduces cardiovascular events in type 2 diabetes (T2DM) and is associated with a reduction in left ventricular (LV) mass index. However, the impact on right ventricular (RV) remodeling is unknown. Accordingly, the objective of this study was to assess the impact of SGLT2 inhibition on RV parameters and function in T2DM and coronary artery disease (CAD).

Methods: In EMPA-HEART CardioLink-6, 97 patients with T2DM and CAD were randomly assigned to empagliflozin $10 \mathrm{mg}(\mathrm{n}=49)$ once daily or placebo $(n=48)$. Cardiac magnetic resonance imaging was performed at baseline and after 6 months. RV mass index (RVMi), RV end-diastolic and end-systolic volume index (RVEDVi, RVESVi) and RV ejection fraction (RVEF) were assessed in blinded fashion.

Results: At baseline, mean RVMi ( \pm SD) $\left(11.8 \pm 2.4 \mathrm{~g} / \mathrm{m}^{2}\right)$, RVEF (53.5 $\left.\pm 4.8 \%\right)$, RVEDVi $\left(64.3 \pm 13.2 \mathrm{~mL} / \mathrm{m}^{2}\right)$ and RVESVi $\left(29.9 \pm 6.9 \mathrm{~mL} / \mathrm{m}^{2}\right)$ were within normal limits and were similar between the empagliflozin and placebo groups. Over 6 months, there were no significant differences in RVMi $\left(-0.11 \mathrm{~g} / \mathrm{m}^{2},[95 \% \mathrm{Cl}-0.81\right.$ to 0.60$\left.], p=0.76\right)$, RVEF (0.54\%, [95\% $\mathrm{Cl}-1.4$ to 2.4$], p=0.58)$, RVEDVi $\left(-1.2 \mathrm{~mL} / \mathrm{m}^{2}\right.$, [95\% $\mathrm{Cl}-4.1$ to 1.7$\left.], p=0.41\right)$ and RVESVi $\left(-0.81 \mathrm{~mL} / \mathrm{m}^{2},[95 \%\right.$ $\mathrm{Cl}-2.5$ to 0.90$], \mathrm{p}=0.35$ ) in the empaglifozin group as compared with the placebo group. In both groups, there was no significant correlation between RVMi and LVMi changes from baseline to 6 months.

Conclusions: In this post-hoc analysis, SGLT2 inhibition with empagliflozin had no impact on RVMi and RV volumes in patients with T2DM and CAD. The potentially differential effect of empagliflozin on the LV and RV warrants further investigation.

Clinical Trial Registration: URL: https://www.clinicaltrials.gov/ct2/show/NCT02998970?cond=NCT02998970\&draw $=2 \&$ rank=1. Unique identifier: NCT02998970.
\end{abstract}

Keywords: Type 2 diabetes, Right ventricle, Sodium-glucose transporter 2 inhibition

*Correspondence: kim.connelly@unityhealth.to; andrew.yan@unityhealth.to ${ }^{1}$ Division of Cardiology, Terrence Donnelly Heart Centre, St Michael's Hospital, 30 Bond Street, Toronto, ON M5B 1W8, Canada

Full list of author information is available at the end of the article

\section{Introduction}

The sodium-glucose cotransporter 2 (SGLT2) inhibitor empagliflozin reduces cardiovascular (CV) mortality, allcause mortality and heart failure (HF) hospitalization in patients with type 2 diabetes (T2DM) and established atherosclerotic CV disease (ASCVD) [1]. Other SGLT2 inhibitors have also been evaluated in large CV outcome original author(s) and the source, provide a link to the Creative Commons licence, and indicate if changes were made. The images or other third party material in this article are included in the article's Creative Commons licence, unless indicated otherwise in a credit line to the material. If material is not included in the article's Creative Commons licence and your intended use is not permitted by statutory regulation or exceeds the permitted use, you will need to obtain permission directly from the copyright holder. To view a copy of this licence, visit http://creativecommons.org/licenses/by/4.0/. The Creative Commons Public Domain Dedication waiver (http://creativeco mmons.org/publicdomain/zero/1.0/) applies to the data made available in this article, unless otherwise stated in a credit line to the data. 
trials in those at risk for, or with established ASCVD, and have shown similar results [2-5]. More recently, the benefit of empagliflozin and dapagliflozin was confirmed in patients with HF with reduced ejection fraction with or without T2DM [6-8].

The mechanism of these benefits, particularly on reducing HF hospitalizations and CV death, remains unclear. In diabetic kidney disease, canagliflozin was associated with attenuated or decreased levels of biomarkers that suggest an effect on molecular processes related to inflammation, the extracellular matrix and fibrosis [9]. Other proposed non-atherothrombotic mechanisms of SGLT2 inhibition include natriuresis, osmotic diuresis, a reduction in preload and afterload, and inhibition of the cardiac sodium-hydrogen exchanger [10-12]. However, whether and how these mediators alter cardiac structure and function remain incompletely understood.

The EMPA-HEART CardioLink- 6 trial demonstrated that compared with placebo, the addition of empagliflozin to antihyperglycemic treatment in individuals with T2DM and coronary artery disease was associated with a significant reduction in left ventricular (LV) mass index (LVMi) as measured by cardiac magnetic resonance imaging (cMRI). Treatment with empagliflozin was also associated with a significant lowering of ambulatory systolic blood pressure with no impact on the circulating levels of NT-pro B-type natriuretic peptide (NT-proBNP) [13].

cMRI provides the reference standard assessment of right ventricular (RV) structure and function [14], which are prognostic markers in various clinical settings including ischemic cardiomyopathy [15], non-ischemic cardiomyopathy [16], HF [17] and a multiethnic population free of CV disease [18]. T2DM affects RV remodeling, systolic and diastolic function, even in the setting of preserved LV ejection fraction (LVEF) [19-21]. Furthermore, T2DM is associated with RV dysfunction following ST elevation myocardial infarction [22]. However, the effects of SGLT2 inhibition on RV structure and function are unknown.

The primary objective of this post-hoc analysis of the EMPA-HEART CardioLink- 6 was to assess using cMRI whether empagliflozin alters RV parameters, function and remodeling among patients with T2DM and established coronary artery disease. The secondary objective was to examine the relationships of RV remodeling with LV remodeling, blood pressure and select cardiac biomarkers.

\section{Methods}

Trial design

This study is a post-hoc analysis of the EMPA-HEART (Effects of Empagliflozin on Cardiac Structure in Patients with Type 2 Diabetes) CardioLink-6 trial
(Unique identifier: NCT02998970), the details of which have been described [13]. In short, EMPA-HEART CardioLink- 6 was a single centre, double-blind, randomized, placebo-controlled, investigator-initiated phase IV trial of empagliflozin in 97 adult patients with T2DM, HbA1c $\geq 6.5 \%$ and $\leq 10 \%$ on stable background antihyperglycemic therapy, estimated glomerular filtration rate $\geq 60 \mathrm{~mL} / \mathrm{min} / 1.73^{2}$ and previous myocardial infarction or coronary revascularization. At baseline, participants underwent clinical and laboratory assessment, and were evaluated with 24-h ambulatory blood pressure monitoring as well as cMRI. Recruited patients were randomized in a 1:1 ratio to 6 months of empagliflozin $10 \mathrm{mg}$ daily or placebo in addition to standard of care. Clinical visits were performed three times over the 6-month follow-up period. Standard transthoracic echocardiography was performed at baseline and 6 months. Right ventricular systolic pressure (RVSP), tricuspid regurgitation peak velocity, tricuspid annular plane systolic excursion (TAPSE) and RV S' were assessed. The final visit included a repeat cMRI and 24-h ambulatory blood pressure monitoring.

\section{Cardiac magnetic resonance imaging}

cMRI scans were performed using a standardized protocol at baseline and 6 months using a clinical 3T MRI scanner (MAGNETOM Skyra; Siemens Healthcare, Erlangen, Germany). A steady-state free-precession sequence was used for standard cine imaging covering the entire LV and RV, typically with $8-12$ contiguous short-axis images without interslice gap. Images were acquired in the supine position and at end-expiration.

Image post-processing was performed offline using CVi 42 (Circle Cardiovascular, Calgary, Alberta, Canada) and was blinded to clinical data as well as the timing of image acquisition. Contouring was performed by a single cardiovascular imaging fellow (BS), over read by two level 3 cMRI readers (ATY and KAC). Endocardial borders at end-diastole and at end-systole in contiguous short-axis images were manually traced (Fig. 1). The epicardial borders at end-diastole were also traced. The difference in area at end-diastole was multiplied by the slice thickness and the sum of these differences throughout the entire RV was multiplied by the myocardial specific density $\left(1.05 \mathrm{~g} / \mathrm{cm}^{3}\right)$ to calculate the RV mass (RVM). RV trabeculations were considered part of the blood pool and not as a part of the RVM. RV end-diastolic and end-systolic volumes (RVEDV and RVESV) were determined by summing the volume across slices without geometric assumptions, and RV ejection fraction (RVEF) was calculated as (RVEDV-RVESV)/RVEDV $\times 100 \%)$. 


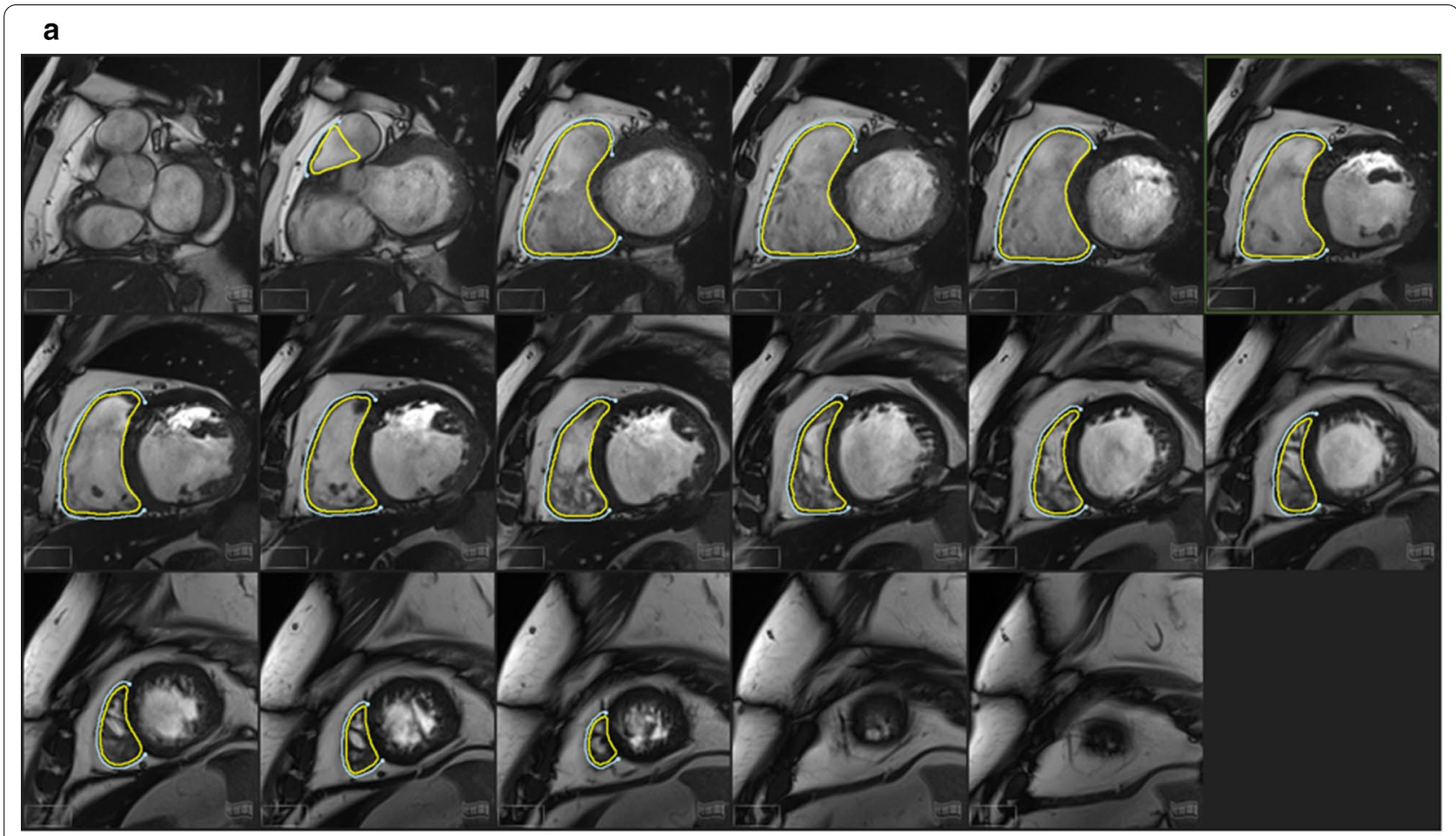

b
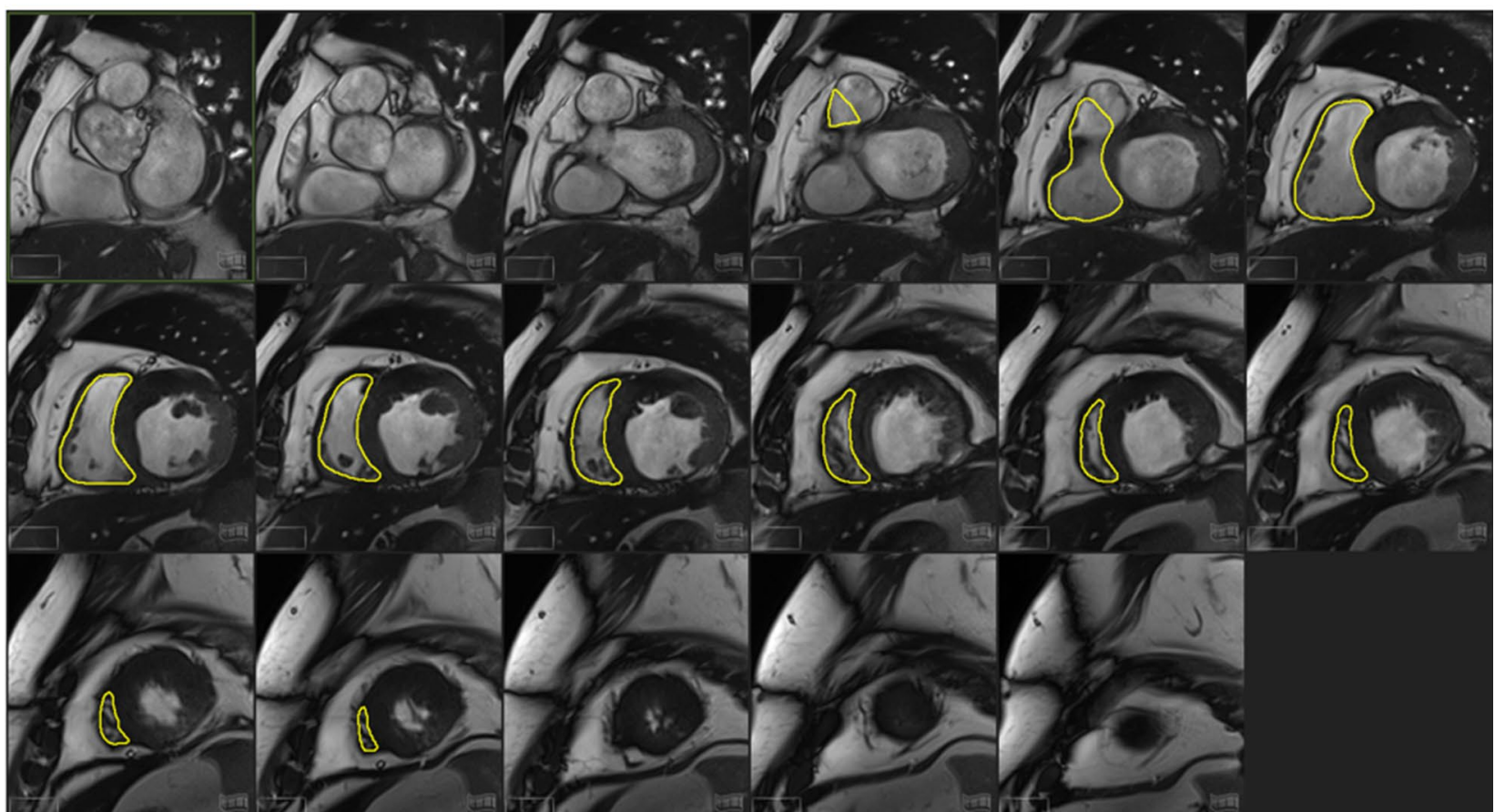

Fig. 1 Example of contouring of the right ventricular endocardium (yellow) and epicardium (blue) in one patient at end-diastole (a) and end-systole (b). Endocardial borders at end-diastole and at end-systole in contiguous short-axis images were manually traced. The epicardial borders at end-diastole were also traced. The difference in area at end-diastole was multiplied by the slice thickness and the sum of these differences throughout the entire right ventricle was multiplied by the myocardial specific density to calculate right ventricular mass. Right ventricular trabeculations were considered part of the blood pool 


\section{Study outcomes}

In this substudy, the primary outcome measure was the change in RVM from baseline to 6 months indexed to the body surface area at baseline (RVMi). Secondary outcomes included the baseline to 6-month changes in RVEDV and RVESV indexed to body surface area (RVEDVi, RVESVi), and RV ejection fraction (RVEF).

\section{Statistical analysis}

All analyses followed an intent-to-treat approach. Categorical variables were presented using counts and percentages and were compared using the $\chi^{2}$ test. Continuous variables are presented as either mean (standard deviation) and compared with the Student's t-test, or as median (interquartile range) and compared with the Kruskal-Wallis test. Spearman's (nonparametric) correlation was used to assess the relationships between RV parameters and LV parameters, blood pressure, NT-proBNP and high sensitivity troponin I. Analysis of covariance (ANCOVA) was used to compare primary and secondary outcomes between the two randomized arms, adjusting for the baseline measurements. Intra-observer variability in the measurement of RV parameters was assessed by intraclass correlation coefficient for absolute agreement using 20 randomly selected studies. Analysis was performed using SPSS 25 (IBM) and statistical significance was set at a two-sided $\mathrm{p}$ value $<0.05$.

\section{Results}

Of the 97 participants enrolled, 49 were assigned to empagliflozin $10 \mathrm{mg} /$ day and 48 to placebo. Among those randomized, 6-month outcome data were unavailable for 7 (5 in the treatment group and 2 in the placebo group). Of these, 3 patients refused and 2 did not undergo follow-up cMRI. Two other patients were lost to followup. Accordingly, both baseline and 6-month cMRI were available for 44 participants in the empagliflozin group and 46 in the placebo arm.

The demographics and baseline characteristics of those randomized were previously published [13] and are summarized in Table 1. Mean (SD) baseline LVMi and LVEF were $59.3(10.9) \mathrm{g} / \mathrm{m}^{2}$ and $58.0(7.5) \%$ in the empagliflozin group, and $62.2(12.8) \mathrm{g} / \mathrm{m}^{2}$ and $55.5(8.7) \%$ in the placebo group, respectively. The change in LVMi from baseline to 6 months was $-2.6(7.8) \mathrm{g} / \mathrm{m}^{2}$ for the empagliflozin group and $-0.01(5.7) \mathrm{g} / \mathrm{m}^{2}$ for the placebo group (adjusted between group difference $-3.35 \mathrm{~g} / \mathrm{m}^{2}, 95 \%$ CI [-5.9, $-0.81], p=0.01)$. There was no significant change in LV end-systolic or end-diastolic indices or LVEF from baseline to 6 months.

Mean (SD) baseline RVMi was $11.5(2.35) \mathrm{g} / \mathrm{m}^{2}$ and $12.8(2.37) \mathrm{g} / \mathrm{m}^{2}$ in the empagliflozin and placebo groups, respectively (Table 2). Mean RVMi, RVEF, RV diastolic and systolic volumes were all within normal limits [23]. Over 6 months, there were no significant differences in RVMi $\left(-0.11 \mathrm{~g} / \mathrm{m}^{2}\right.$, [95\% CI -0.81 to 0.60$], \mathrm{p}=0.76$ ), RVEF (0.54\%, [95\% CI -1.4 to 2.4 ], $\mathrm{p}=0.58$ ), RVEDVi $\left(-1.2 \mathrm{~mL} / \mathrm{m}^{2}\right.$, [95\% CI -4.1 to 1.7$\left.], \mathrm{p}=0.41\right)$ and RVESVi $\left(-0.81 \mathrm{~mL} / \mathrm{m}^{2}\right.$, [95\% CI -2.5 to 0.90$\left.], \mathrm{p}=0.35\right)$ in the empaglifozin group as compared with the placebo group by ANCOVA adjusting for baseline values. Intraclass correlation coefficient values for absolute agreement in the measurement of RV parameters were $>0.95$ for RVMi, RVEDVi, RVESVi and 0.86 for RVEF. Adjusted between group differences (mean, 95\% CI) using ANCOVA are displayed in Table 2 and Fig. $2 \mathrm{a}-\mathrm{d}$.

Mean (SD) baseline RVSP and tricuspid regurgitation peak velocity were $22.8(6.5) \mathrm{mmHg}$ and $2.2(0.38) \mathrm{m} / \mathrm{s}$ in 14 patients in the empagliflozin group, and 20.7 (4.4) $\mathrm{mmHg}$ and $2.1(0.27) \mathrm{m} / \mathrm{s}$ in 17 patients in the placebo group, respectively. The remaining subjects had missing data due to an insufficient tricuspid regurgitation spectral Doppler profile. Echocardiographic parameters that assess RV function were normal at baseline and unchanged at 6 months: -0.099 (95\% CI [ -2.8 to 0.08$]$, $\mathrm{p}=0.28)$ for TAPSE and $-0.32(95 \% \mathrm{CI}[-1.2$ to 0.52$]$, $\mathrm{p}=0.45$ ) for RV $\mathrm{S}^{\prime}$.

The relationships between RV parameters and LV parameters, blood pressure and biomarkers were evaluated. In both groups, there was no significant correlation between RVMi and LVMi changes from baseline to 6-month follow up (Table 3). However, there was a significant correlation between the changes in RV and LV endsystolic and end-diastolic indexed volumes. The change in RVEF and LVEF were correlated in the control group but not the empagliflozin group. There was no significant correlation between changes in RV parameters with changes in NT-pro-BNP, high sensitivity troponin I, systolic or diastolic blood pressure (Table 4).

\section{Discussion}

In this post-hoc analysis of the EMPA-HEART CardioLink-6 trial, the addition of empagliflozin to stable antihyperglycemic therapy in patients with T2DM and established coronary artery disease without HF did not result in significant changes in RVMi, RV volumes or RVEF over 6 months, as measured by cMRI. To our knowledge, this is the first cMRI study to assess changes in RV parameters and function in a randomized controlled trial of an SGLT2 inhibitor.

There has been considerable work conducted to delineate how SGLT2 inhibition affects the $\operatorname{LV}[24,25]$. The EMPA-HEART CardioLink- 6 trial demonstrated that after 6 months of treatment with empagliflozin, there was a decrease in LVMi without a change in LV volumes or LVEF [13]. A substudy of this trial showed that 
Table 1 Baseline characteristics of the study population

\begin{tabular}{|c|c|c|}
\hline & Empagliflozin $10 \mathrm{mg}(\mathrm{n}=44)$ & Placebo $(n=46)$ \\
\hline Age, years* & $64(57,69)$ & $64(56,72)$ \\
\hline Body mass index, $\mathrm{kg} / \mathrm{m}^{2 *}$ & $26.7(24.5,30.2)$ & $26.6(24.4,29.3)$ \\
\hline Body surface area, $m^{2 *}$ & $2.0(1.8,2.1)$ & $1.9(1.8,2.1)$ \\
\hline Male sex & 90 & 96 \\
\hline Smoking history & 41 & 46 \\
\hline Duration of type 2 diabetes, years* & $10.0(4.0,15.0)$ & $10.0(5.0,15.0)$ \\
\hline Hypertension & 92 & 90 \\
\hline History of myocardial infarction & 39 & 44 \\
\hline History of percutaneous coronary intervention $>2$ months before screening & 53 & 40 \\
\hline History of coronary artery bypass surgery $>2$ months before screening & 57 & 56 \\
\hline History of heart failure & 4.0 & 8.0 \\
\hline History of peripheral artery disease & 4.0 & 6.0 \\
\hline History of transient ischemic attack or stroke & 16 & 13 \\
\hline Serum creatinine, mg/dL* & $0.9(0.8,1.0)$ & $0.9(0.8,1.0)$ \\
\hline Hemoglobin A1c, \%* & $7.9(7.5,8.4)$ & $7.9(7.3,8.7)$ \\
\hline Hematocrit, \%* & $0.42(0.40,0.46)$ & $0.42(0.39,0.44)$ \\
\hline Systolic blood pressure, $\mathrm{mmHg}^{*}$ & $128(120,143)$ & $134(125,146)$ \\
\hline Diastolic blood pressure, $\mathrm{mmHg}^{*}$ & $74(69,82)$ & $77(71,81)$ \\
\hline Heart rate, bpm* & $67(60,77)$ & $68(60,76)$ \\
\hline \multicolumn{3}{|l|}{ Cardiac MRI data } \\
\hline Left ventricular mass, g & $116.5(26.3)$ & $120.9(33.0)$ \\
\hline Left ventricular mass index, $\mathrm{g} / \mathrm{m}^{2}$ & $59.3(10.9)$ & $62.2(12.8)$ \\
\hline Left ventricular end diastolic volume index, $\mathrm{mL} / \mathrm{m}^{2}$ & $63.3(15.5)$ & $71.4(15.4)$ \\
\hline Left ventricular end systolic volume index. $\mathrm{mL} / \mathrm{m}^{2}$ & $27.1(10.5)$ & $32.3(11.8)$ \\
\hline Left ventricular ejection fraction. \% & $58.0(7.5)$ & $55.5(8.7)$ \\
\hline \multicolumn{3}{|l|}{ Echocardiographic data } \\
\hline Right ventricular systolic pressure, $\mathrm{mmHg} \dagger$ & $22.8(6.5)$ & $20.7(4.4)$ \\
\hline Peak tricuspid regurgitation velocity, $\mathrm{m} / \mathrm{s} \dagger$ & $2.2(0.38)$ & $2.1(0.27)$ \\
\hline Tricuspid annular plane systolic excursion, $\mathrm{cm}$ & $2.0(1.2)$ & $1.8(0.5)$ \\
\hline Right ventricular S', mm & $10.4(2.7)$ & $10.9(2.9)$ \\
\hline \multicolumn{3}{|l|}{ Biomarkers } \\
\hline NT-pro B-type natriuretic peptide, pg/mL* & $97.0(46.0,190)$ & $116(59.0,230)$ \\
\hline High sensitivity troponin I, ng/mL* & $0.03(0.03,0.20)$ & $0.03(0.03,0.03)$ \\
\hline \multicolumn{3}{|l|}{ Medications at baseline } \\
\hline Aspirin/P2Y12 inhibitor & 82 & 85 \\
\hline Beta blocker & 78 & 81 \\
\hline Calcium channel blocker & 12 & 31 \\
\hline Angiotensin converting enzyme inhibitor/angiotensin receptor blocker & 82 & 85 \\
\hline Statin & 96 & 96 \\
\hline Insulin & 25 & 25 \\
\hline Metformin & 96 & 92 \\
\hline
\end{tabular}

Data expressed as percentages or mean (standard deviation) unless otherwise specified

*Median (25th, 75th percentile)

tData available for 14 in the empagliflozin group and 17 in the placebo group

empagliflozin exposure also resulted in a decrease in extracellular compartment volume as measured by cMRI [26]. In the SUGAR-DM-HF trial, which enrolled a more advanced HF population, empagliflozin also reduced LV end-diastolic and end-systolic volume index [27].
The RV is considerably different from the LV with respect to its structure, function, loading conditions and adaptation in states of disease [28]. Importantly, there is a paucity of information on how SGLT2 inhibition affects the morphology and function of the RV [29]. This 


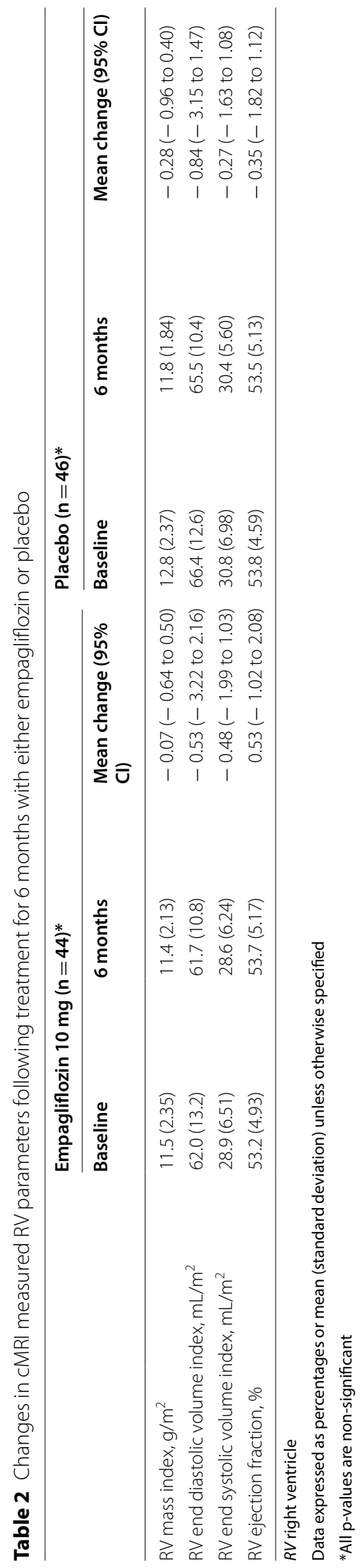




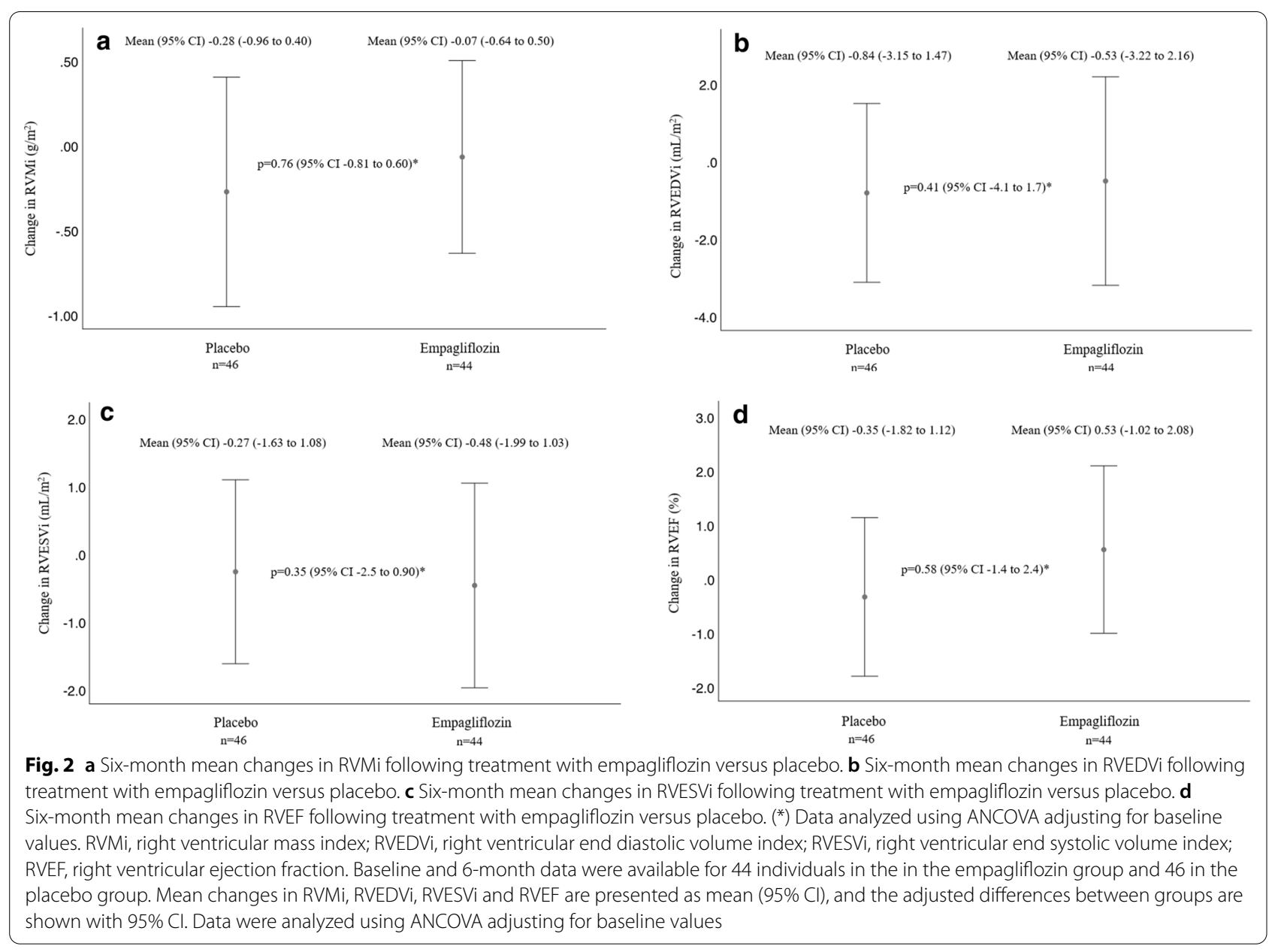

Table 3 Spearman's correlation coefficients for the relationships between changes in right and left ventricular indices over 6 months

\begin{tabular}{|c|c|c|c|c|c|c|}
\hline & \multicolumn{2}{|c|}{ Both groups $(n=90)$} & \multicolumn{2}{|c|}{ Empagliflozin $10 \mathrm{mg}(\mathrm{n}=44)$} & \multicolumn{2}{|c|}{ Placebo $(n=46)$} \\
\hline & $\begin{array}{l}\text { Spearman's } \\
\text { correlation }\end{array}$ & $p$-value & $\begin{array}{l}\text { Spearman's } \\
\text { correlation }\end{array}$ & p-value & $\begin{array}{l}\text { Spearman's } \\
\text { correlation }\end{array}$ & p-value \\
\hline Mass index, $\mathrm{g} / \mathrm{m}^{2}$ & 0.16 & 0.14 & 0.30 & 0.05 & 0.07 & 0.64 \\
\hline End diastolic volume index, $\mathrm{mL} / \mathrm{m}^{2}$ & 0.58 & $<0.001$ & 0.52 & $<0.001$ & 0.54 & $<0.001$ \\
\hline End systolic volume index, $\mathrm{mL} / \mathrm{m}^{2}$ & 0.43 & $<0.001$ & 0.36 & 0.02 & 0.44 & 0.002 \\
\hline Ejection fraction, \% & 0.30 & 0.01 & 0.13 & 0.40 & 0.43 & 0.003 \\
\hline
\end{tabular}

is surprising given that individuals with T2DM may have impaired RV systolic and diastolic function as well as decreased RV volumes, even in the absence of established coronary artery disease or HF [19, 21, 30, 31]. Furthermore, T2DM is associated with RV systolic and diastolic dysfunction in the setting of HF with preserved LVEF, independent of RV afterload [20]. The underlying mechanism for this association remains unclear and has been postulated to be a consequence of hyperglycemia and the deposition of glycosylation products, as well as hyperinsulinemia resulting in myocyte hypertrophy, myocardial steatosis and inflammation [31].

The clinical relevance of RVMi in left-sided HF is not well established, and our current understanding is largely derived from other patient populations that included those with pulmonary hypertension [32]. In the current analysis, empagliflozin $10 \mathrm{mg}$ daily for 6 months did not appear to have any effect on RVMi. This observation 
Table 4 Spearman's correlation coefficients between 6-month changes in right ventricular indices, biomarkers and blood pressure

\begin{tabular}{|c|c|c|c|c|c|c|c|c|}
\hline \multirow[t]{2}{*}{ Biomarker } & \multicolumn{4}{|c|}{ Empagliflozin $10 \mathrm{mg}(\mathrm{n}=44)^{*}$} & \multicolumn{4}{|c|}{ Placebo $(n=46)^{*}$} \\
\hline & RVEDVI & RVESVI & RVMI & RVEF & RVEDVI & RVESVI & RVMI & RVEF \\
\hline NT-pro-BNP, pg/mL & 0.04 & -0.06 & 0.06 & 0.11 & -0.05 & -0.18 & 0.06 & 0.15 \\
\hline High sensitivity troponin I, ng/mL & 0.19 & 0.26 & 0.17 & -0.16 & -0.02 & -0.15 & 0.07 & 0.26 \\
\hline Systolic blood pressure & 0.03 & 0.06 & 0.04 & 0.03 & 0.15 & 0.26 & -0.02 & -0.21 \\
\hline Diastolic blood pressure & -0.10 & -0.09 & 0.01 & 0.06 & 0.06 & 0.13 & 0.12 & -0.19 \\
\hline
\end{tabular}

NT-pro-BNP, NT-pro B-natriuretic peptide

*All p-values are non-significant

contrasts with the decrease in LVMi previously observed in the same study cohort [13]. While this difference could be attributed to the RV not being exposed to systemic afterload, it should be noted that the LVMi regression occurred independent of blood pressure changes. These discordant findings suggest that there may be other mechanisms, independent of afterload, which differentially affect the LV, RV, systemic and pulmonary vasculature.

In the Multi-Ethnic Study of Atherosclerosis, RVM by cMRI was positively associated with systolic blood pressure in 4204 individuals who were free of $\mathrm{CV}$ disease [33]. In a cMRI study that assessed RV remodeling in 25 hypertensive patients, systemic hypertension was also associated with greater RVMi and concentric RV remodeling. Although these changes were associated with LV remodeling, it was not reported if there was any correlation with pulmonary artery pressure [34]. Conversely, in our study, there was no significant correlation between changes in RVMi and changes in systemic systolic or diastolic blood pressure, despite a decrease in blood pressure in the group randomized to empagliflozin.

It remains unknown whether SGLT2 inhibition may have an effect on the RV in left-sided HF with combined pre- and post-capillary pulmonary hypertension. Animal models provide some insight with regard to pulmonary artery hypertension. In one study, empagliflozin significantly improved survival in rats with monocrotaline-induced pulmonary artery hypertension while reducing mean pulmonary artery pressure; this was accompanied by reduced RV hypertrophy and fibrosis [35]. The EMBRACE-HF trial showed that in patients with NYHA class III-IV HF and CardioMEMS pulmonary artery pressure sensors (mean pulmonary artery diastolic pressure $22 \mathrm{mmHg}$, median NT-proBNP $637 \mathrm{pg} / \mathrm{mL}$ ), empagliflozin decreased pulmonary artery pressures independent of loop diuretic therapy [36]. RV remodeling in this context was not investigated, however, the change in mean and diastolic pulmonary artery pressure was under $2 \mathrm{mmHg}$, which would not be expected to meaningfully impact RV parameters and function.

Our cohort likely had a low prevalence of group 2 pulmonary hypertension since RVSP and tricuspid regurgitation peak velocity values were not elevated [37]. Moreover, NT-pro-BNP levels were within the normal range [38] and patients with HF were excluded. In the EMPA-HEART CardioLink-6 echocardiographic substudy, the majority of patients demonstrated only grade 1 diastolic dysfunction with mostly normal left atrial size [39], suggesting that our study population had normal filling pressures; our findings should not be extrapolated to those with pulmonary hypertension or HF. While SGLT2 inhibition may impact ventricular interdependence by altering filling pressures, diastolic function, systolic blood pressure and pulmonary pressures, the effect should not be significant in this cohort. However, it is likely to be more important in other populations and under different loading conditions.

RV volumes and RVEF in the EMPA-HEART cohort were in the normal range, as were LV volumes and LVEF. Moreover, NT-pro-BNP values were normal. Indeed, in the SUGAR-DM-HF trial, which enrolled patients with T2DM, LVEF $<40 \%$, and NYHA class II-IV symptoms, empagliflozin reduced LV end-diastolic and end-systolic volume index as measured by cMRI [27]. RV parameters were not reported. It is plausible that the effect of SGLT2i on the RV, and even mechanism of action, may differ depending on the stage of HF. Our findings should not be extrapolated to those with pulmonary hypertension or advanced HF, particularly with RV dysfunction or hypertrophy, as this is beyond the scope of our study.

Our study has a number of limitations. First, the sample size was small and most of the participants were men, which may be relevant since the relationship between RV volumes and T2DM may differ between sexes [19]. Although the EMPA-HEART CardioLink-6 trial was not powered to assess for changes in the RV, the narrow $95 \%$ confidence intervals afforded by cMRI 
effectively ruled out clinically significant changes in RVMi despite the small sample size. Second, follow up duration was only 6 months. Third, there are technical challenges while contouring the RV including its thinner wall, delineation of the basal slice and artifacts including from sternotomy wires. Fourth, invasive pulmonary pressures were not known and an adequate tricuspid regurgitation spectral Doppler profile was only available in about one third of patients to estimate RVSP. Fifth, tissue mapping of the RV was not performed as part of this study.

There are also important strengths. First, to the best of our knowledge, this is the first substudy of a randomized placebo-controlled trial utilizing cMRI to assess the effect of SGLT2 inhibition on RV parameters and function. Second, cMRI is the gold standard assessment of the RV and is independent of geometric assumption. Image analysis was performed with blinding and good intra-observer variability, and all RV measurements were made independent of LV measurements.

\section{Conclusion}

In this post-hoc analysis of the EMPA-HEART CardioLink-6 trial, in contrast to the LV, SGLT2 inhibition with empagliflozin had no impact on RVMi in patients with T2DM, coronary artery disease and normal LVEF. The potentially differential effect of empagliflozin on the LV and RV warrants further investigation.

\begin{abstract}
Abbreviations
ANCOVA: Analysis of covariance; ASCVD: Atherosclerotic cardiovascular disease; CV: Cardiovascular; CMRI: Cardiac magnetic resonance imaging; EDV(i): End systolic volume (index); EF: Ejection fraction; ESV(i): End systolic volume (index); HF: Heart failure; LV: Left ventricle; LVM(i): Left ventricular mass (index); NT-pro-BNP: NT-pro B-type natriuretic peptide; RV: Right ventricle; RVM(i): Right ventricular mass (index); RVSP: Right ventricular systolic pressure; SGLT2: Sodium-glucose transporter 2; TAPSE: Tricuspid annular plane systolic excursion; T2DM: Type 2 diabetes.
\end{abstract}

\section{Acknowledgements}

We are indebted to all of those who contributed to the EMPA-HEART CardioLink- 6 trial, and to Sue Francis for her assistance in the preparation of this manuscript.

\section{Authors' contributions}

BS performed all cardiac MRI contouring and analysis. ATY and KAC over read all cardiac MRI contours. BS was the primary author of the manuscript. All authors read and approved the final manuscript.

\section{Funding}

The EMPA-HEART CardioLink- 6 trial was supported by an unrestricted investigator-initiated study grant from Boehringer Ingelheim.

\section{Availability of data and materials}

All data generated or analysed during this study are included in this published article (an its Additional files).

\section{Declarations}

Ethics approval and consent to participate

The study design and protocol were reviewed and approved by the St. Michael's Hospital Research Ethics Board, and all participants provided informed consent.

\section{Consent for publication}

Not applicable.

\section{Competing interests}

Bradley Sarak, None. Subodh Verma, Tier 1 Canada Research Chair in Cardiovascular Surgery. Research grant support and/or speaking honoraria from Amarin (modest), Amgen (modest), AstraZeneca (significant), Bayer (modest), Boehringer Ingelheim (signficiant), Bristol-Myers Squibb (modest), Eli Lilly (significant), EOCI Pharmacomm Ltd (modest), HLS Therapeutics (significant), Janssen (modest), Merck (modest), Novartis (modest), Novo Nordisk (modest), Pfizer (modest), PhaseBio (significant), Sanofi (modest), Sun Pharmaceuticals (significant), and the Toronto Knowledge Translation Working Group (signifcant). President of the Canadian Medical and Surgical Knowledge Translation Research Group, a federally incorporated not-for-profit physician organization. C. David Mazer, Research grant support and/or speaking/consulting honoraria from Amgen, Boehringer Ingelheim, and OctaPharma (all modest). Hwee Teoh, Consulting honoraria from Boehringer Ingelheim and manuscript writing fees for unrelated topics from Merck and Servier (all modest). Adrian Quan, None. Richard E. Gilbert, Canada Research Chair in Diabetes Complications. Research grant support and/or speaking/consulting honoraria from AstraZeneca, Bayer, Boehringer Ingelheim, Janssen (all significant). Shaun G. Goodman, Research grant support (including steering committee or data and safety monitoring committees) and/or speaker/consulting honoraria (including advisory boards) from: Amgen, AstraZeneca, Bayer, Boehringer Ingelheim, Bristol Myers Squibb, CSL Behring, Daiichi-Sankyo/American Regent, Eli Lilly, Esperion, Ferring Pharmaceuticals, GlaxoSmithKline, HLS Therapeutics, JAMP Pharma, Janssen/Johnson \& Johnson, Merck, Novartis, Novo Nordisk A/C, Pendopharm, Pfizer, Regeneron, Sanofi, Servier, Valeo Pharma; and salary support/honoraria from the Heart and Stroke Foundation of Ontario/University of Toronto (Polo) Chair, Canadian Heart Research Centre and MD Primer, Canadian VIGOUR Centre, Cleveland Clinic Coordinating Centre for Clinical Research, Duke Clinical Research Institute, New York University Clinical Coordinating Centre, and PERFUSE Research Institute (all relationships significant except Pendopharm, Servier, and Valeo). Karan Bami, Conference support from Boehringer Ingelheim (modest). Otávio R Coelho-Filho, None. Vineeta Ahooja, Research grant support and/or speaking/consulting honoraria AstraZeneca, Bayer, Boehringer Ingelheim, NovoNordisk. Sublnvestigator for EMPEROR PRESERVED, EMPEROR REDUCED, EMPA HEART, DELIVER, DETERMINE, DapaHF, SOLOIST, PRIORITIZE, SELECT, EMPACT MI (all modest). Djeven P. Deva, None. Vinay Garg, None. Sumeet Gandhi, None. Kim A. Connelly, Research grant support and/or speaking/consulting honoraria from Abbott Vascular, AstraZeneca, Boehringer Ingelheim, Bristol Myers Squibb, Edwards, Eli Lilly, Janssen, Merck, Novo Nordisk, Sanofi, Servier (all significant). Andrew T. Yan, Research grant support from AstraZeneca (modest).

\section{Author details}

${ }^{1}$ Division of Cardiology, Terrence Donnelly Heart Centre, St Michael's Hospital, 30 Bond Street, Toronto, ON M5B 1W8, Canada. ${ }^{2}$ University of Toronto, Toronto, Canada. ${ }^{3}$ Keenan Research Centre, Li Ka Shing Knowledge Institute, St Michael's Hospital, Toronto, Canada. ${ }^{4}$ Division of Cardiac Surgery, St Michael's Hospital, Toronto, Canada. ${ }^{5}$ Department of Anesthesia, St Michael's Hospital, Toronto, Canada. ${ }^{6}$ Division of Endocrinology and Metabolism, St Michael's Hospital, Toronto, Canada. ${ }^{7}$ Department of Internal Medicine, Discipline of Cardiology, State University of Campinas, Campinas, Brazil. ${ }^{8}$ Heart Health Institute, Toronto, ON, Canada. ${ }^{9}$ Department of Medical Imaging, St. Michael's Hospital, Toronto, Canada. ${ }^{10}$ Trillium Health Partners, Toronto, Canada.

Received: 26 July 2021 Accepted: 23 September 2021

Published online: 04 October 2021 


\section{References}

1. Zinman B, Wanner C, Lachin JM, Fitchett D, Bluhmki E, Hantel S, Mattheus M, Devins T, Johansen OE, Woerle HJ, EMPA-REG OUTCOME Investigators, et al. Empagliflozin, cardiovascular outcomes, and mortality in type 2 diabetes. N Engl J Med. 2015;373:2117-28.

2. Neal B, Perkovic V, Mahaffey KW, de Zeeuw D, Fulcher G, Erondu N, Shaw W, Law G, Desai M, Matthews DR, CANVAS Program Collaborative Group. Canagliflozin and cardiovascular and renal events in type 2 diabetes. $\mathrm{N}$ Engl J Med. 2017:377:644-57.

3. Wiviott SD, Raz I, Bonaca MP, Mosenzon O, Kato ET, Cahn A, Silverman MG, Zelniker TA, Kuder JF, Murphy SA, DECLARE-TIMI 58 Investigators, et al. Dapagliflozin and cardiovascular outcomes in type 2 diabetes. N Engl J Med. 2019:380:347-57.

4. Bhatt DL, Szarek M, Steg PG, Cannon CP, Leiter LA, McGuire DK, Lewis JB, Riddle MC, Voors AA, Metra M, SOLOIST-WHF Trial Investigators, et al. Sotagliflozin in patients with diabetes and recent worsening heart failure. N Engl J Med. 2021;384:117-28.

5. Cannon CP, Pratley R, Dagogo-Jack S, Mancuso J, Huyck S, Masiukiewicz U, Charbonnel B, Frederich R, Gallo S, Cosentino F, VERTIS CV Investigators, et al. Cardiovascular outcomes with ertugliflozin in type 2 diabetes. $\mathrm{N}$ Engl J Med. 2020;383:1425-35

6. McMurray JJV, DeMets DL, Inzucchi SE, Køber L, Kosiborod MN, Langkilde AM, Martinez FA, Bengtsson O, Ponikowski P, Sabatine MS, DAPA-HF Committees and Investigators, et al. A trial to evaluate the effect of the sodium-glucose co-transporter 2 inhibitor dapagliflozin on morbidity and mortality in patients with heart failure and reduced left ventricular ejection fraction (DAPA-HF). Eur J Heart Fail. 2019;21:665-75.

7. Packer M, Anker SD, Butler J, Filippatos G, Pocock SJ, Carson P, Januzzi J, Verma S, Tsutsui H, Brueckmann M, EMPEROR-Reduced Trial Investigators, et al. Cardiovascular and renal outcomes with empagliflozin in heart failure. N Engl J Med. 2020:383:1413-24.

8. Zannad F, Ferreira JP, Pocock SJ, Anker SD, Butler J, Filippatos G, Brueckmann M, Ofstad AP, Pfarr E, Jamal W, et al. SGLT2 inhibitors in patients with heart failure with reduced ejection fraction: a meta-analysis of the EMPEROR-reduced and DAPA-HF trials. Lancet. 2020;396:819-29.

9. Heerspink HJL, Perco P, Mulder S, Leierer J, Hansen MK, Heinzel A, Mayer $G$. Canagliflozin reduces inflammation and fibrosis biomarkers: a potential mechanism for action for beneficial effects on SGLT2 inhibitors in diabetic kidney disease. Diabetologia. 2019;62:1154-66.

10. Verma S, McMurray JJV, Cherney DZI. The metabolodiuretic promise of sodium-dependent glucose cotransporter 2 inhibition: the search for the sweet spot in heart failure. JAMA Cardiol. 2017;2:939-40.

11. Chin KL, Ofori-Asenso R, Hopper I, von Lueder TG, Reid CM, Zoungas S, Wang BH, Liew D. Potential mechanisms underlying the cardiovascular benefits of sodium glucose cotransporter 2 inhibitors: a systematic review of data from preclinical studies. Cardiovasc Res. 2019;115:266-76.

12. Verma S, McMurray JJV. SGLT2 inhibitors and mechanisms of cardiovascular benefit: a state-of-the-art review. Diabetologia. 2018;61:2108-17.

13. Verma S, Mazer CD, Yan AT, Mason T, Garg V, Teoh H, Zuo F, Quan A, Farkouh ME, Fitchett $\mathrm{DH}$, et al. Effect of empagliflozin on left ventricular mass in patients with type 2 diabetes mellitus and coronary artery disease: the EMPA-HEART CardioLink-6 randomized clinical trial. Circulation. 2019:140:1693-702

14. Hudsmith LE, Petersen SE, Francis JM, Robson MD, Neubauer S. Normal human left and right ventricular and left atrial dimensions using steady state free precession magnetic resonance imaging. J Cardiovasc Magn Reson. 2005:7:775-82

15. Sabe MA, Sabe SA, Kusunose K, Flamm SD, Griffin BP, Kwon DH. Predictors and prognostic significance of right ventricular ejection fraction in patients with ischemic cardiomyopathy. Circulation. 2016;134:656-65.

16. Gulati A, Ismail TF, Jabbour A, Alpendurada F, Guha K, Ismail NA, Raza S, Khwaja J, Brown TD, Morarji K, et al. The prevalence and prognostic significance of right ventricular systolic dysfunction in nonischemic dilated cardiomyopathy. Circulation. 2013;12:1623-33.

17. Di Salvo TG, Mathier M, Semigran MJ, Dec GW. Preserved right ventricular ejection fraction predicts exercise capacity and survival in advanced heart failure. J Am Coll Cardiol. 1995;25:1143-53.

18. Kawut SM, Barr RG, Lima JA, Praestgaard A, Johnson WC, Chahal H, Ogunyankin KO, Bristow MR, Kizer JR, Tandri H, et al. Right ventricular structure is associated with the risk of heart failure and cardiovascular death: the
Multi-Ethnic Study of Atherosclerosis (MESA)-right ventricle study. Circulation. 2012;126:1681-8.

19. Patscheider H, Lorbeer R, Auweter S, Schafnitzel A, Bayerl C, Curta A, Rathmann W, Heier M, Meisinger C, Peters A, et al. Subclinical changes in $\mathrm{MRI}$-determined right ventricular volumes and function in subjects with prediabetes and diabetes. Eur Radiol. 2018;28:3105-13.

20. Gorter TM, Streng KW, van Melle JP, Rienstra M, Dickinson MG, Lam CSP, Hummel YM, Voors AA, Hoendermis ES, van Veldhuisen DJ. Diabetes mellitus and right ventricular dysfunction in heart failure with preserved ejection fraction. Am J Cardiol. 2017;121:621-7.

21. Linssen PBC, Veugen MGJ, Henry RMA, van der Kallen CJH, Kroon AA, Schram MT, Brunner-La Rocca HP, Stehouwer CDA. Associations of (pre) diabetes with right ventricular and atrial structure and function: the Maastricht Study. Cardiovasc Diabetol. 2020;19:88.

22. Roifman I, Ghugre N, Zia M, Farkouh ME, Zavodni A, Wright GA, Connelly $K A$. Diabetes is an independent predictor of right ventricular dysfunction post ST-elevation myocardial infarction. Cardiovasc Diabetol. 2016;15:34.

23. Kawel-Boehm N, Hetzel SJ, Ambale-Venkatesh B, Captur G, Francois CJ, Jerosch-Herold M, Salerno M, Teague SD, Valsangiacomo-Buechel E, van der Geest RJ, et al. Reference ranges ("normal values") for cardiovascular magnetic resonance (CMR) in adult and children: 2020 update. J Cardiovasc Magn Reson. 2020;22:87.

24. Lan NSR, Fegan PG, Yeap BB, Dwivedi G. The effects of sodium-glucose cotransporter 2 inhibitors on left ventricular function: current evidence and future directions. ESC Heart Fail. 2019;6:927-35.

25. Yu YW, Zhao XM, Wang YH, Zhou Q, Huang Y, Zhai M, Zhang J. Effect of sodium-glucose cotransporter 2 inhibitors on cardiac structure and function in type 2 diabetes mellitus patients with or without chronic heart failure: a meta-analysis. Cardiovasc Diabetol. 2021;20:25.

26. Mason T, Coelho-Filho OR, Verma S, Chowdhury B, Zuo F, Quan A, Thorpe KE, Bonneau C, Teoh H, Gilbert RE, et al. Empagliflozin reduces myocardial extracellular volume in patients with type 2 diabetes and coronary artery disease. JACC Cardiovasc Imaging. 2021;14:1164-73.

27. Lee MMY, Brooksbank KJM, Wetherall K, Mangion K, Roditi G, Campbell RT, Berry C, Chong V, Coyle L, Docherty KF, et al. Effect of empagliflozin on left ventricular volumes in patients with type 2 diabetes, or prediabetes, and heart failure with reduced ejection fraction (SUGAR-DM-HF). Circulation. 2021;9(143):516-25.

28. Buttrick PM, Walker LA. The right ventricle: biologic insights and response to disease. Curr Cardiol Rev. 2009;5:22-8.

29. Patoulias D, Katsimardou A, Toumpourleka M, Papadopoulos C, Doumas $M$. Time to assess the effects of sodium-glucose co-transporter-2 inhibitors on the 'forgotten' right ventricle? ESC Heart Fail. 2020;7:337-8.

30. Redington AN, Friedberg MK. Right versus left ventricular failure: differences, similarities, and interactions. Circulation. 2014;129:1033-44.

31. Tadic M, Celic V, Cuspidi C, Ilic S, Pencic B, Radojkovic J, Ivanovic B, Stanisavljevic D, Kocabay G, Marjanovic T. Right heart mechanics in untreated normotensive patients with prediabetes and type 2 diabetes mellitus: a two- and three-dimensional echocardiographic study. J Am Soc Echocardiogr. 2015;28:317-27.

32. Saba TS, Foster J, Cockburn M, Cowan M, Peacock AJ. Ventricular mass index using magnetic resonance imaging accurately estimates pulmonary artery pressure. Eur Respir J. 2002;20:1519-24.

33. Chahal H, Johnson C, Tandri H, Jain A, Hundley WG, Barr RG, Kawut SM, Lima JA, Bluemke DA. Relation of cardiovascular risk factors to right ventricular structure and function as determined by magnetic resonance imaging (results from the multi-ethnic study of atherosclerosis). Am J Cardiol. 2010;206:110-6.

34. Todiere G, Neglia D, Ghione S, Fommei E, Capozza P, Guarini G, Dell'omo G, Aquaro GD, Marzilli M, Lombardi M, et al. Right ventricular remodelling in systemic hypertension: a cardiac MRI study. Heart. 2011;97:1257-61.

35. Chowdhury B, Luu AZ, Luu VZ, Kabir MG, Pan Y, Teoh H, Quan A, Sabongui S, Al-Omran M, Bhatt DL, et al. The SGLT2 inhibitor empagliflozin reduces mortality and prevents progression in experimental pulmonary hypertension. Biochem Biophys Res Commun. 2020;524:50-6.

36. Nassif ME, Qintar M, Windsor SL, Jermyn R, Shavelle DM, Tang F, Lamba S, Bhatt K, Brush J, Civitello A, et al. Empagliflozin effects on pulmonary artery pressure in patients with heart failure: results from EMpagliflozin Evaluation By MeasuRing ImpAct on HemodynamiCs in PatiEnts with Heart Failure (EMBRACE-HF) Trial. Circulation. 2021;143:1673-86. 
37. Rudski LG, Lai WW, Afilalo J, Hua L, Handschumacher MD, Chandrasekaran K, Solomon SD, Louie EK, Schiller NB. Guidelines for the echocardiographic assessment of the right heart in adults: a report from the American Society of Echocardiography endorsed by the European Association of Echocardiography, a registered branch of the European Society of Cardiology, and the Canadian Society of Echocardiography. J Am Soc Echocardiogr. 2010;23:685-713.

38. Gan CT, McCann GP, Marcus JT, van Wolferen SA, Twisk JW, Boonstra A, Postmus PE, Vonk-Noordegraaf A. NT-proBNP reflects right ventricular structure and function in pulmonary hypertension. Eur Respir J. 2006;28:1190-4.
39. Bami K, Gandhi S, Leong-Poi H, Yan AT, Ho E, Zahrani M, Garg V, Zuo F, Teoh $\mathrm{H}$, Quan A, et al. Effects of empagliflozin on left ventricular remodeling in patients with type 2 diabetes and coronary artery disease: echocardiographic substudy of the EMPA-HEART CardioLink-6 randomized clinical trial. J Am Soc Echocardiogr. 2020;33:644-6.

\section{Publisher's Note}

Springer Nature remains neutral with regard to jurisdictional claims in published maps and institutional affiliations.
Ready to submit your research? Choose BMC and benefit from:

- fast, convenient online submission

- thorough peer review by experienced researchers in your field

- rapid publication on acceptance

- support for research data, including large and complex data types

- gold Open Access which fosters wider collaboration and increased citations

- maximum visibility for your research: over $100 \mathrm{M}$ website views per year

At BMC, research is always in progress.

Learn more biomedcentral.com/submissions 